Supplement of Geosci. Model Dev., 12, 4443-4467, 2019

https://doi.org/10.5194/gmd-12-4443-2019-supplement

(C) Author(s) 2019. This work is distributed under

the Creative Commons Attribution 4.0 License.

(c) (1)

Supplement of

\title{
Improving permafrost physics in the coupled Canadian Land Surface Scheme (v.3.6.2) and Canadian Terrestrial Ecosystem Model (v.2.1) (CLASS-CTEM)
}

Joe R. Melton et al.

Correspondence to: Joe R. Melton (joe.melton@ canada.ca)

The copyright of individual parts of the supplement might differ from the CC BY 4.0 License. 


\section{Impact of the de Vries (1963) thermal conductivity parameterization}

The Exp. deVries thermal cond. has a smaller average MAE of $0.287 \mathrm{~m}$ than SoilGrids + Moss (0.472 m, Main Figure 3). Comparing the spatial patterns of ALT for deVries thermal cond. with SoilGrids+Moss shows generally deeper ALTs with a large loss of permafrost in the southern zones of the PD in eastern Russia (Main Figure 2 and Figure S5). Global simulated PA 5 drops from 17.9 to $16.2 \mathrm{Mkm}^{2}$. In winter simulations at seven sites in the South Saskatchewan River Basin (SSRB), MacDonald (2015) found the de Vries (1963) soil thermal conductivity formulation to outperform the Côté and Konrad (2005) soil thermal conductivity parameterization in CLASS-CTEM through improvements in both simulated soil moisture and snow. However, the de Vries (1963) formulation neglects the effect of ice on soil thermal conductivity (see equations A7 - A10). As the thermal conductivity of liquid water $\left(0.57 \mathrm{~W} \mathrm{~m}^{-1} \mathrm{~K}^{-1}\right.$ at $\left.5{ }^{\circ} \mathrm{C}\right)$ is much lower than that of ice $\left(2.24 \mathrm{~W} \mathrm{~m}^{-1} \mathrm{~K}^{-1}\right.$ at $\left.-4{ }^{\circ} \mathrm{C}\right)$, it is surprising that this formulation performs as well as it did both in our simulations against the GTN-P ALT observations, and for the SSRB runs conducted by MacDonald (2015). This neglecting of the thermal conductivity difference between liquid water and ice could be the cause of a dampened soil temperature annual cycle as deeper soil layers are slower to cool in the deVries thermal cond. simulations compared to SoilGrids+Moss (Figure S12). We do see an increase in wMAE at the GTN-P borehole sites (Main Figure 4) demonstrating that this parameterization does indeed degrade model performance as would be anticipated.

\section{Impact of driving meteorological dataset}

When the meteorological forcing dataset is CRUJRA55 instead of CRUNCEP, the MAE of both SoilGrids+Moss and Pel16+Moss improves further to $0.415 \mathrm{~m}$ and $0.404 \mathrm{~m}$, respectively, with two fewer cells ISPF (The spatial differences between the Pel16+Moss and SoilGrids+Moss simulations with CRUNCEP and CRUJRA55 are shown in Figure S11). The CRUNCEP meteorological forcing dataset generally produces deeper ALTs for much of Eurasia than simulations forced with CRUJRA55 with some shallower ALTs in Alaska and the Yukon. While CRUNCEP and CRUJRA55 share a common climatology (CRU), it is likely their differences in sub-monthly variability leads to significant differences in simulated PA and ALTs. This result is in line with Beer et al. (2018) who used artificially manipulated climate datasets to show that soil temperature can be 0.1 to 0.8 ${ }^{\circ} \mathrm{C}$ higher when climate variability is reduced in the model forcing data. 


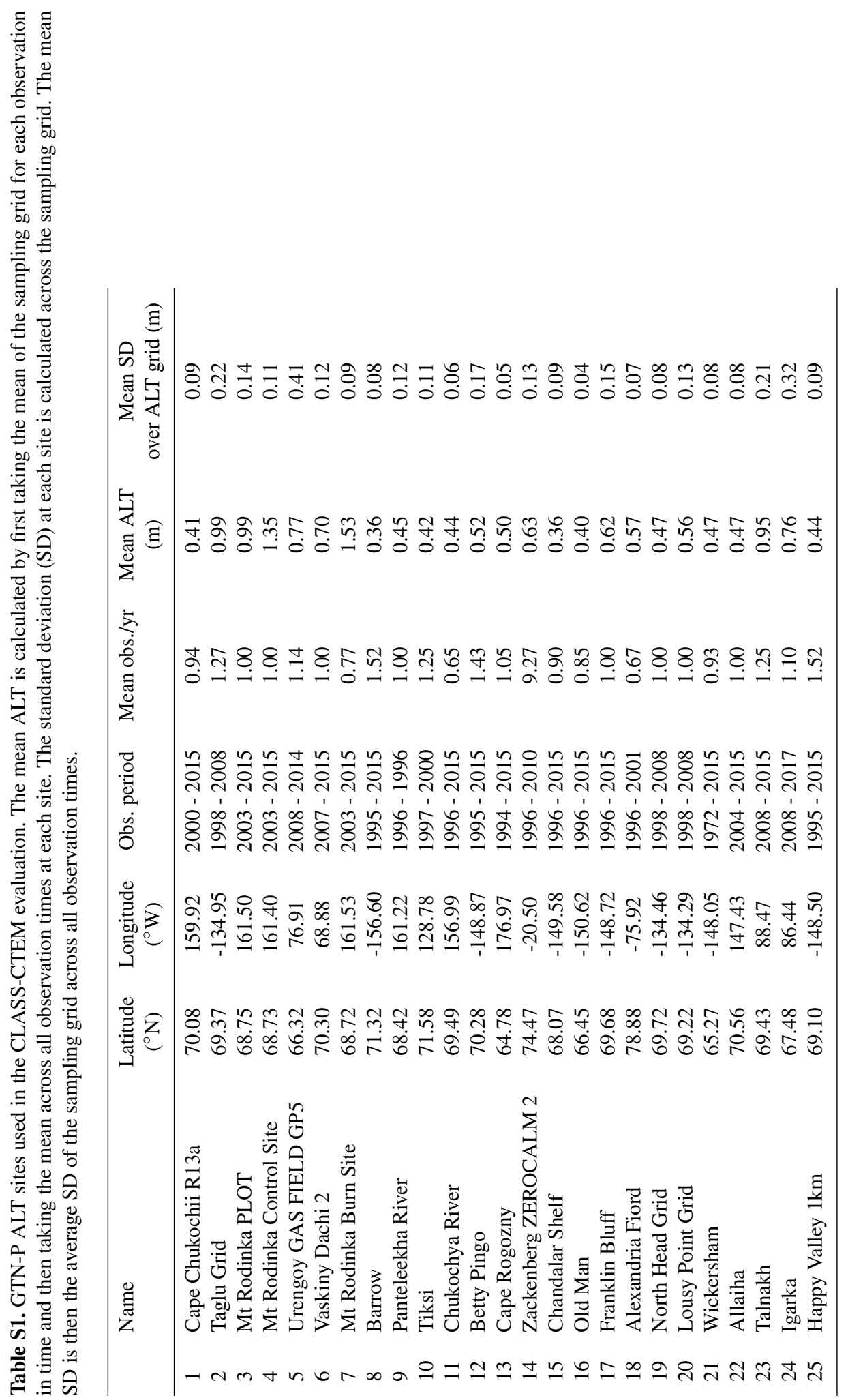




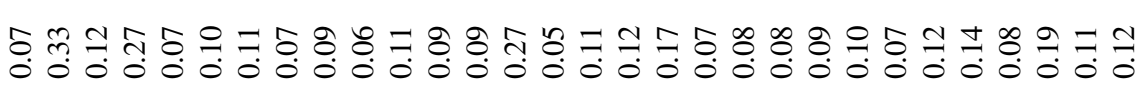

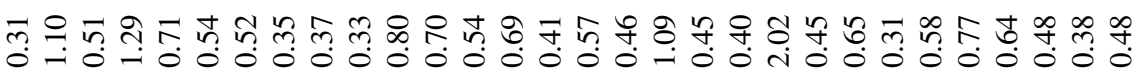

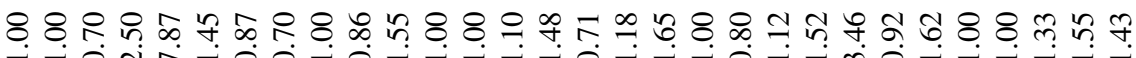

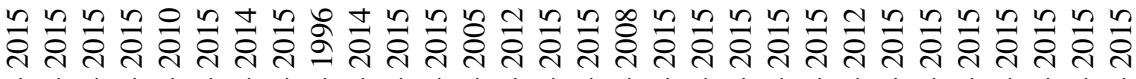

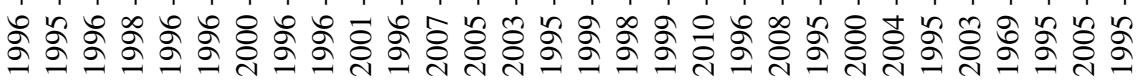

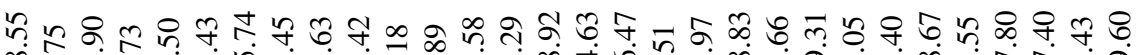

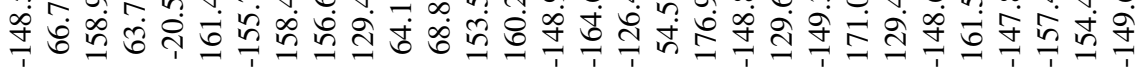

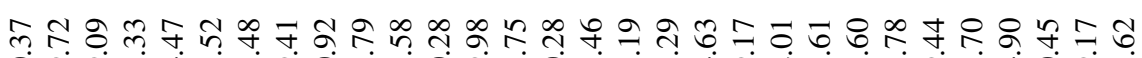

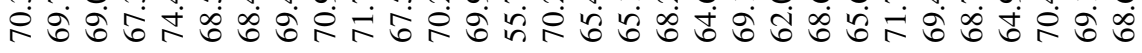

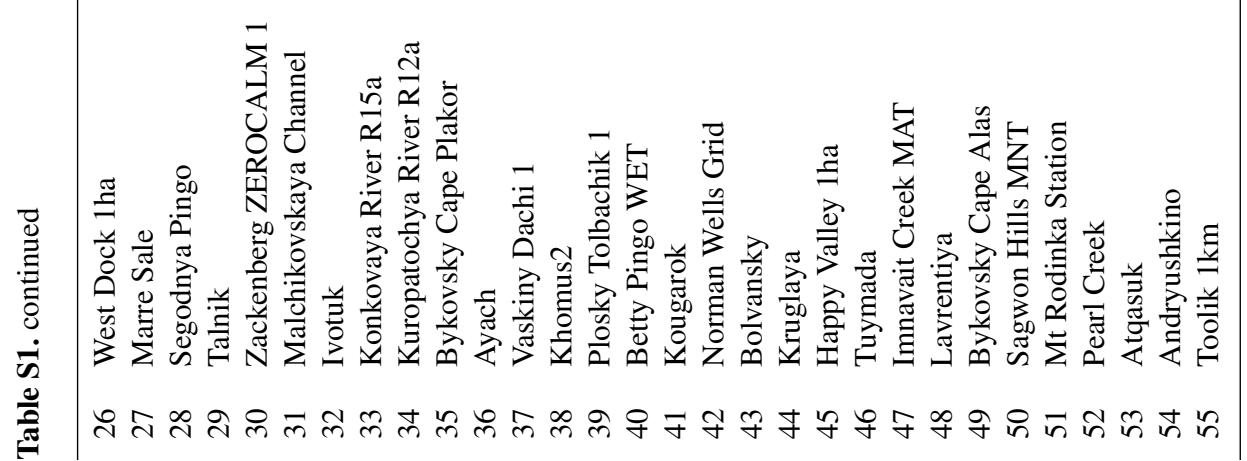




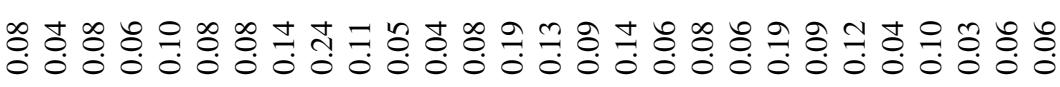

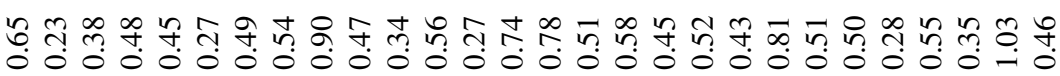

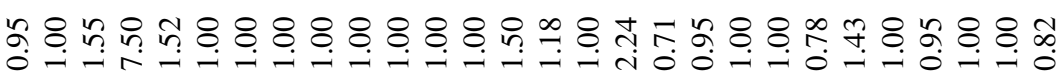

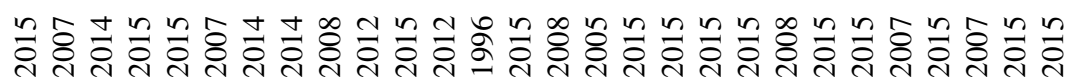
1

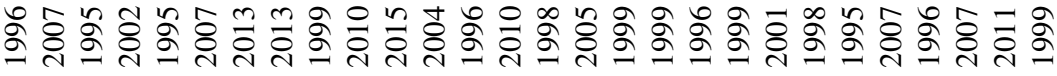

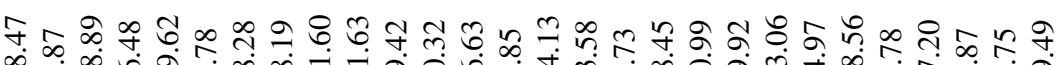

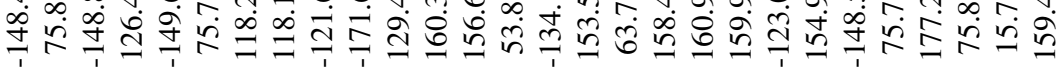

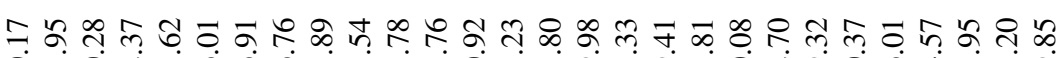
₹

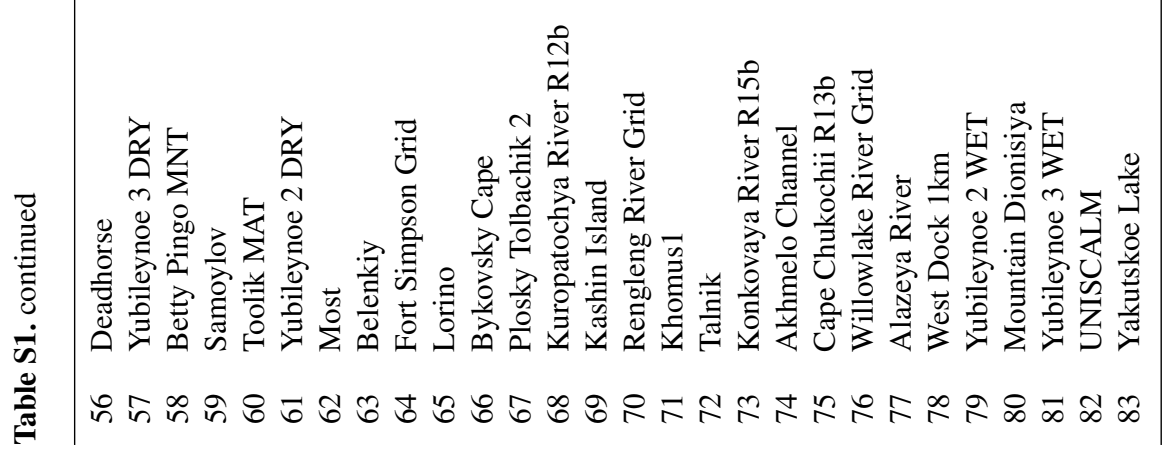




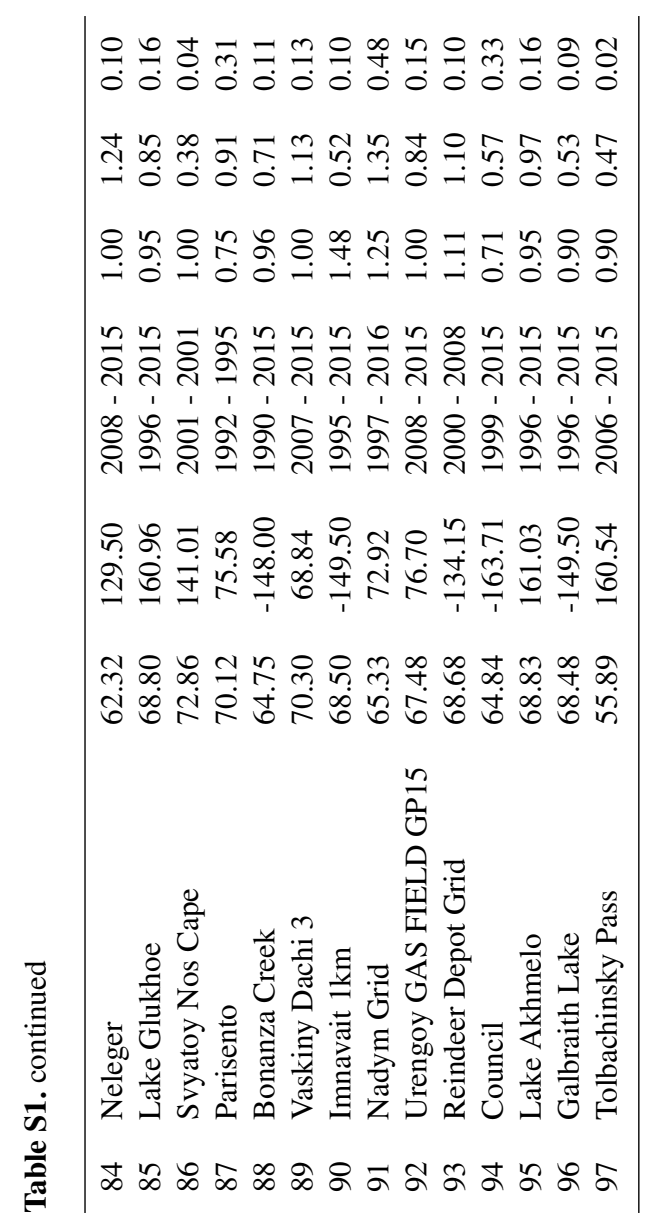




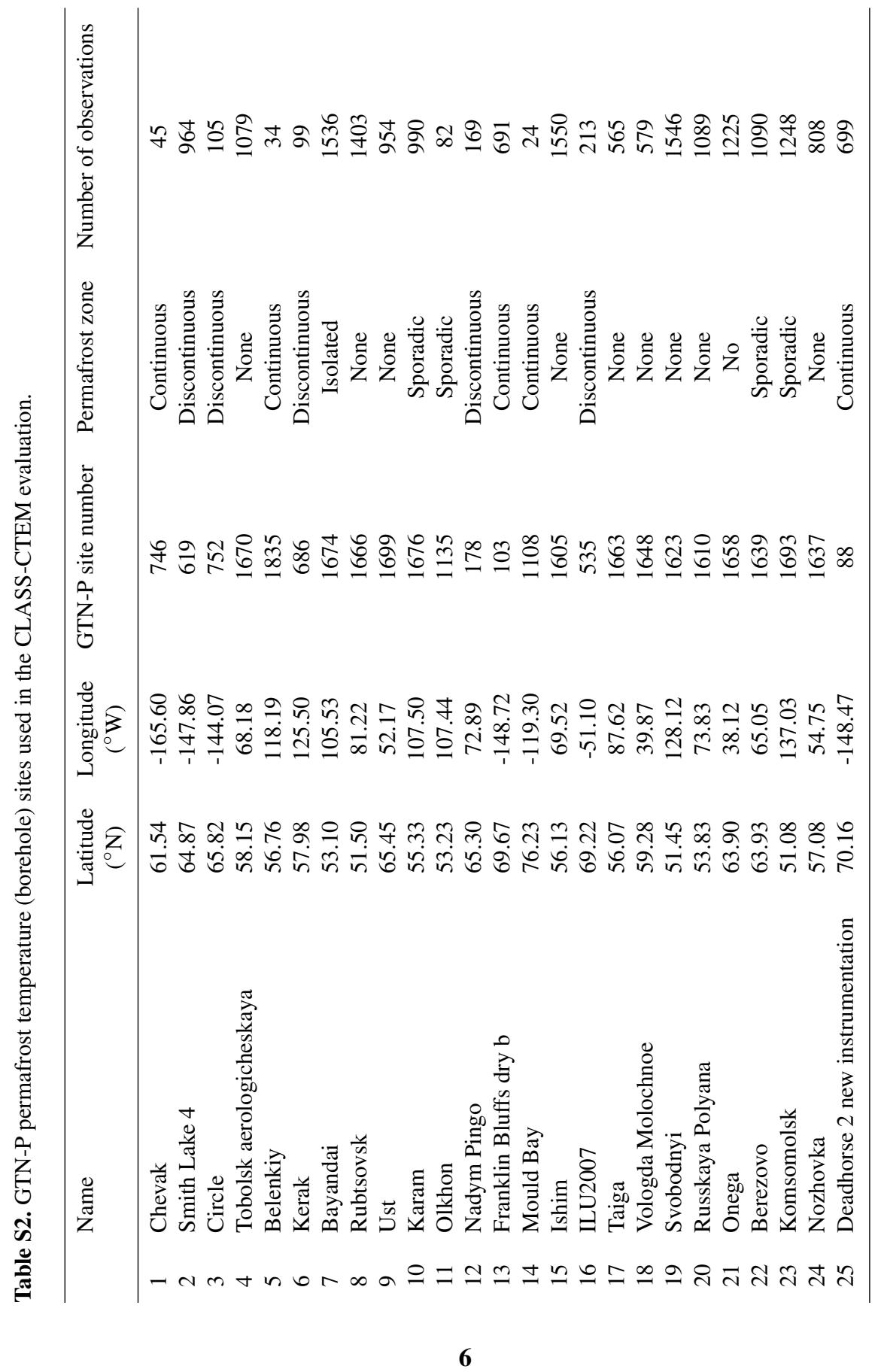




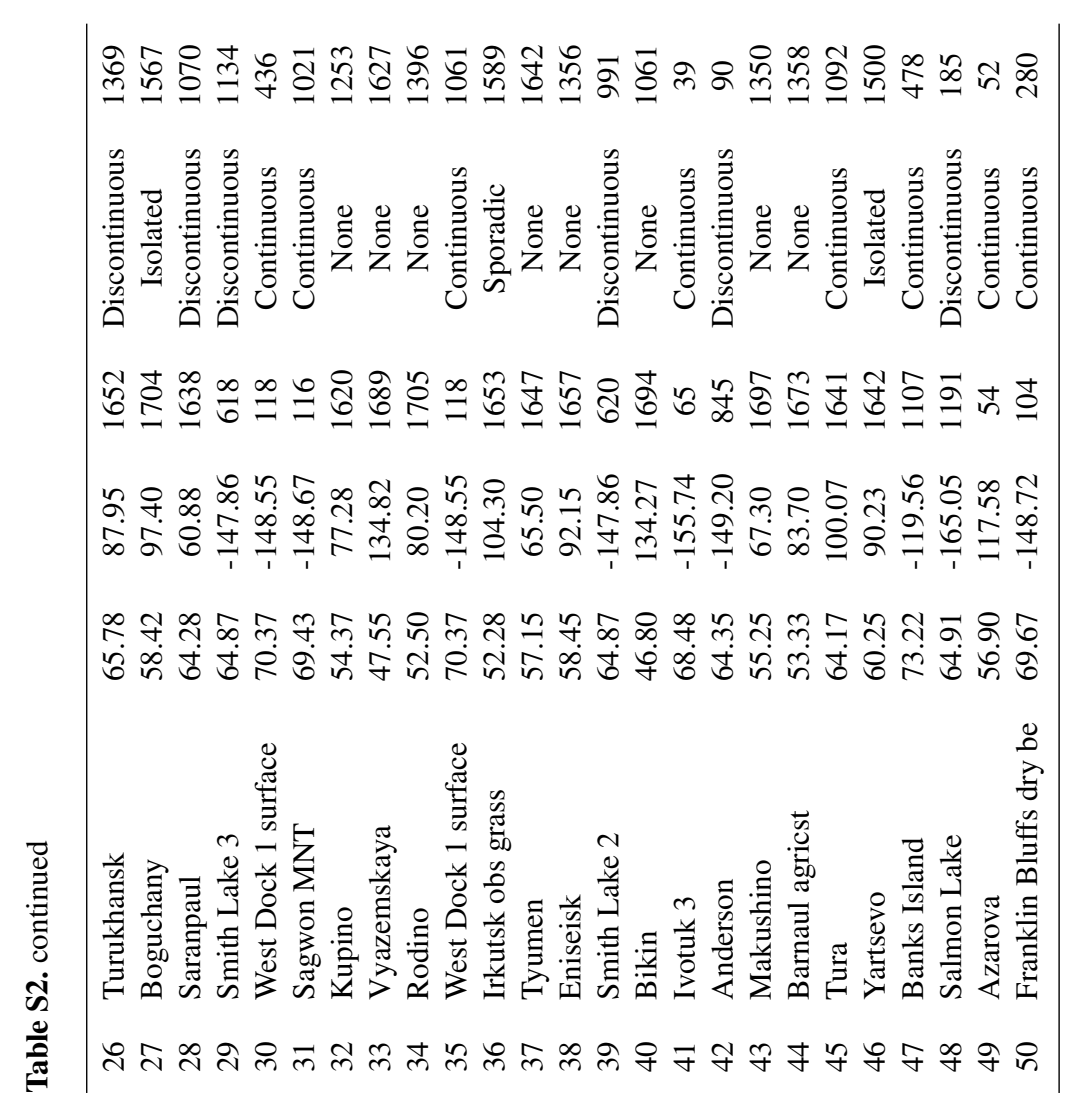




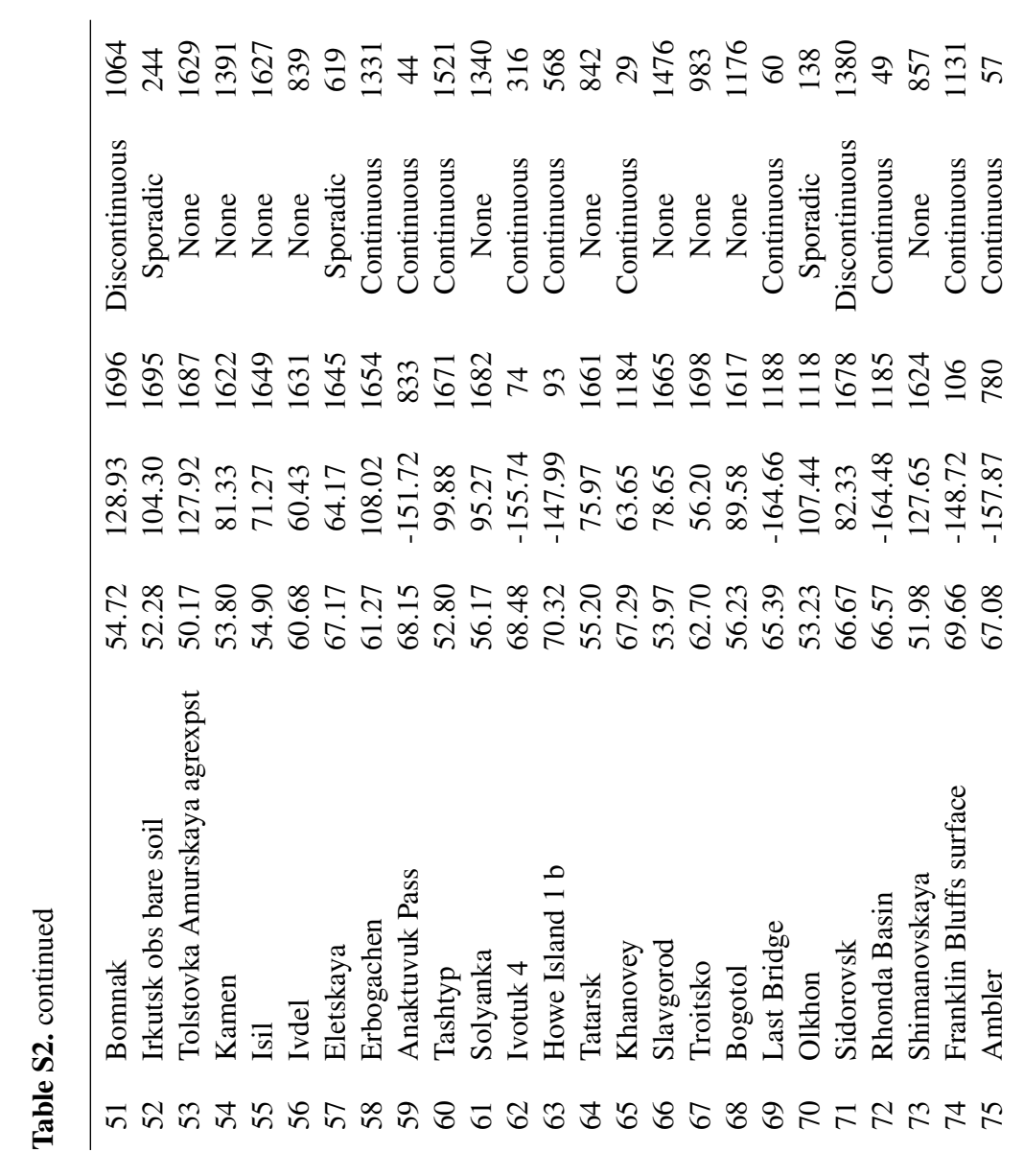




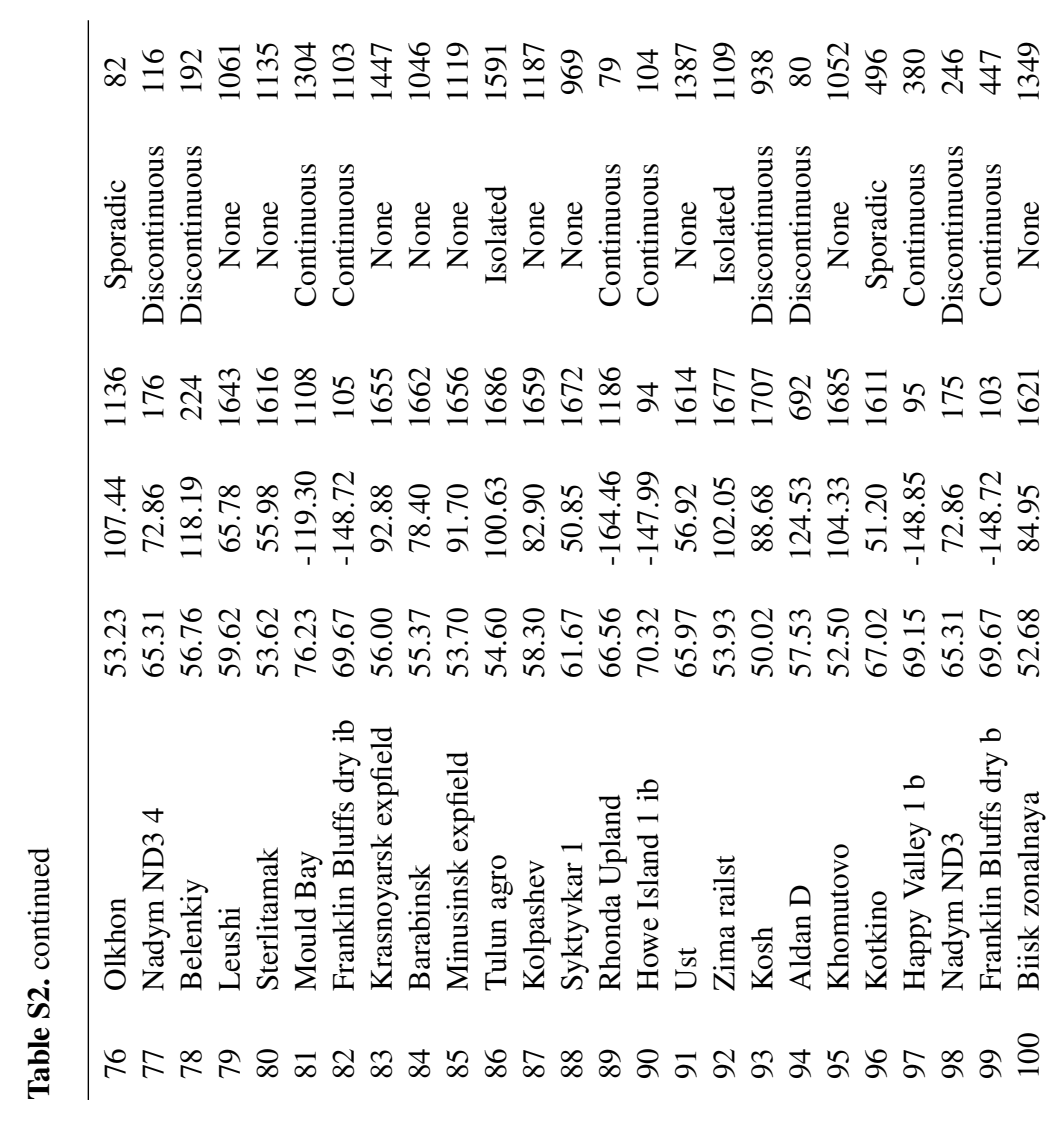




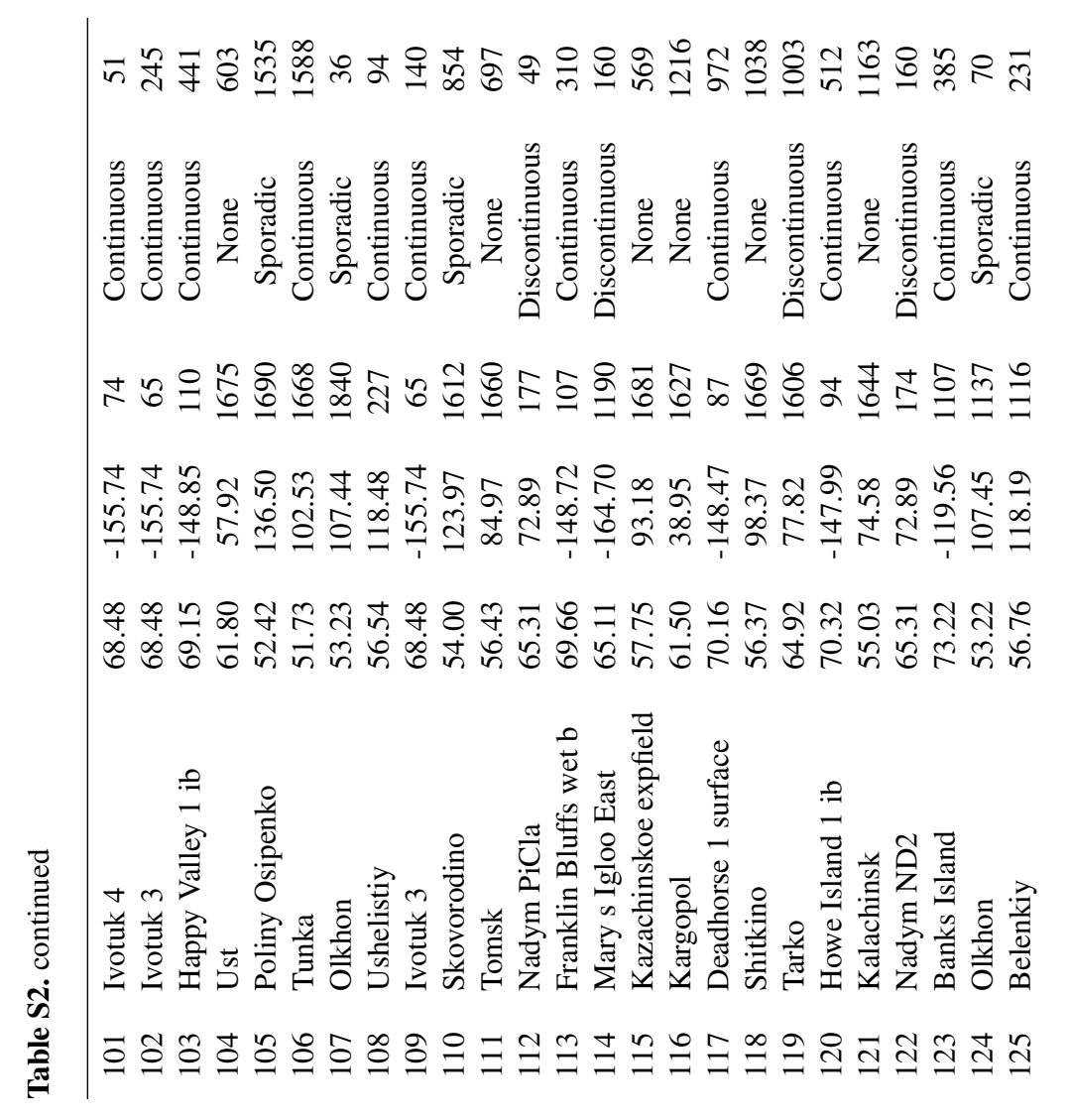




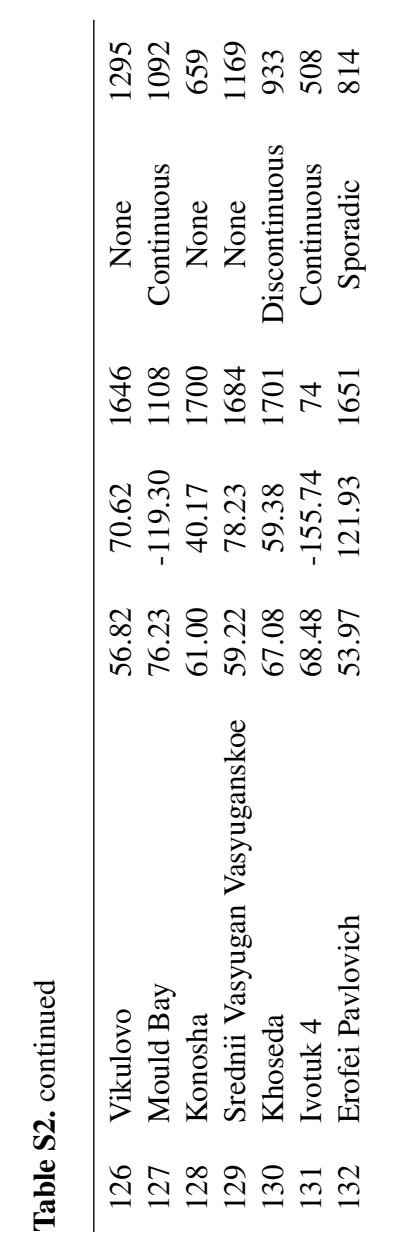



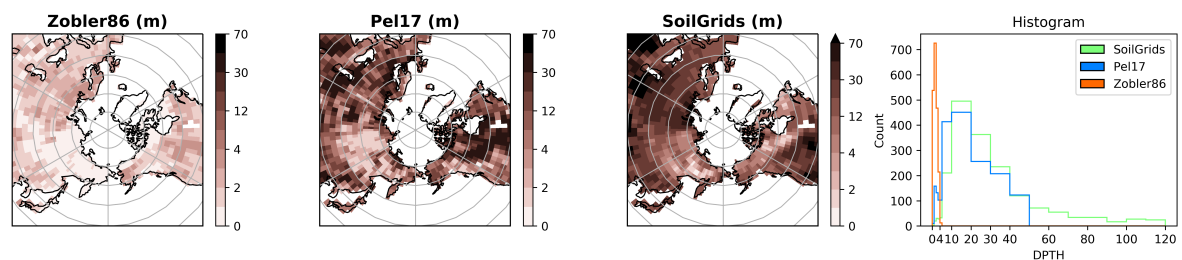

Figure S1. Comparison of soil permeable depth datasets from Zobler86 (Zobler, 1986), Pel16 (Pelletier et al., 2016), and SoilGrids (Shangguan et al., 2017). 


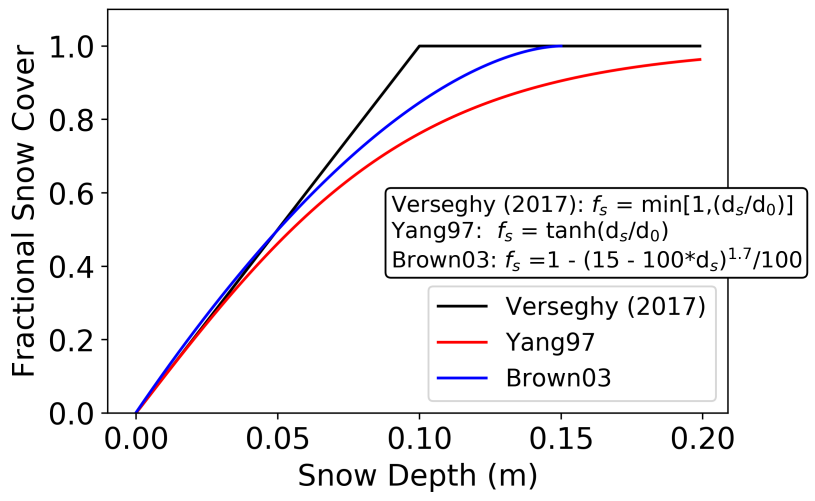

Figure S2. Snow cover as a function of snow depth for the CLASS-CTEM linear relation (Verseghy, 2017), the hyperbolic tangent form of Yang et al. (1997), and the exponential relationship proposed by Brown et al. (2003) 

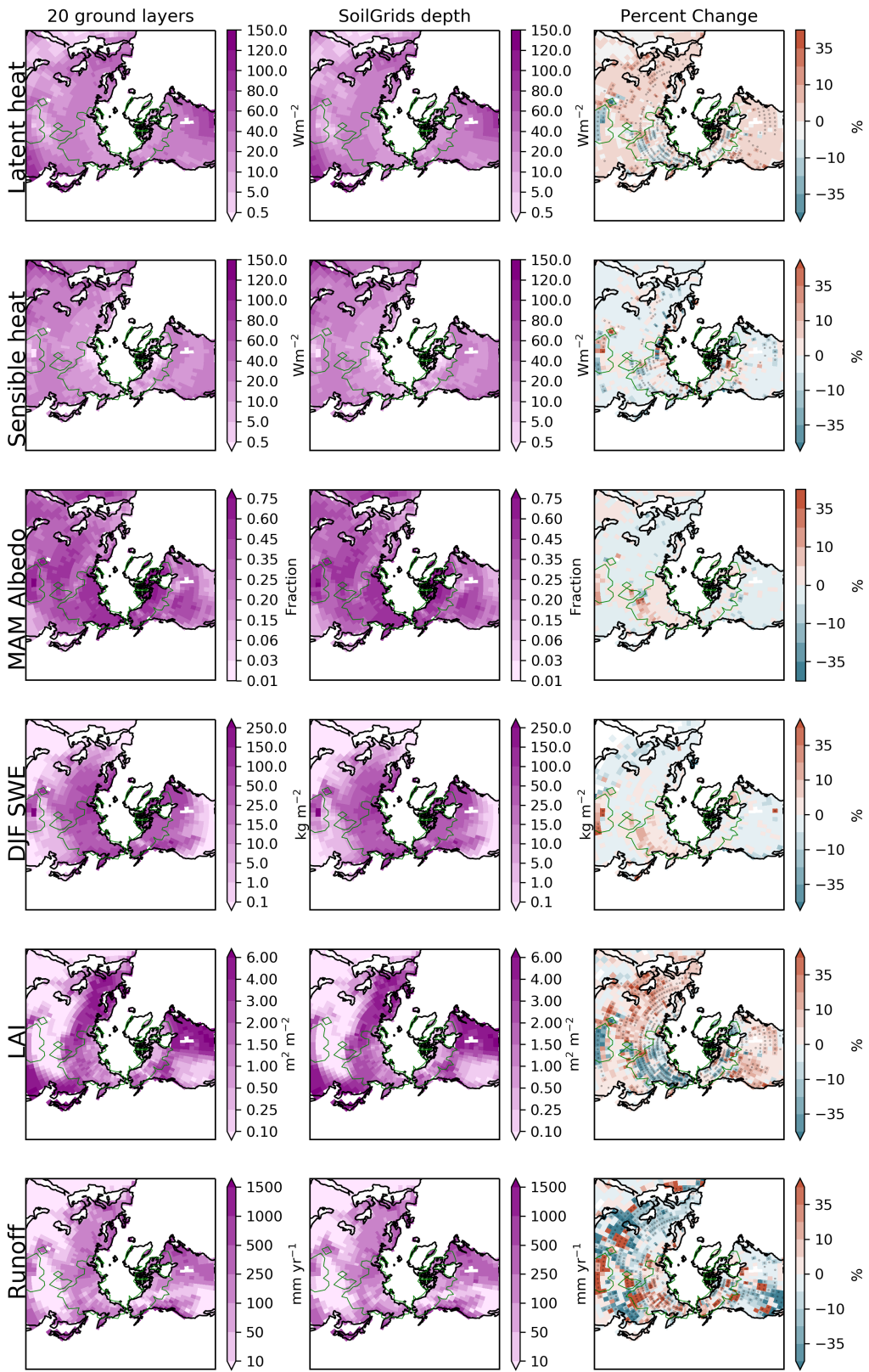

Figure S3. Comparison of mean annual latent and sensible heat flxues, spring (March, April, May; MAM) total surface albedo, winter (December, January, February; DJF) snow water equivalent (SWE), mean annual leaf area index (LAI) and total runoff. Positive percent change values indicate that the '20 ground layer' experiment has higher values of a quantity than the Base model while negative values indicate the opposite. The green polygon indicates regions of permafrost simulated by that experiment. The green polygon on the percent change plots is the permafrost region from the 20 ground layers experiment. Dots indicate grid cells that are statistically significant (independent two-sample t-test p level < 0.05). The left column shows the results from the Exp 20 ground layer while the middle column shows the SoilGrids depth experiment. 

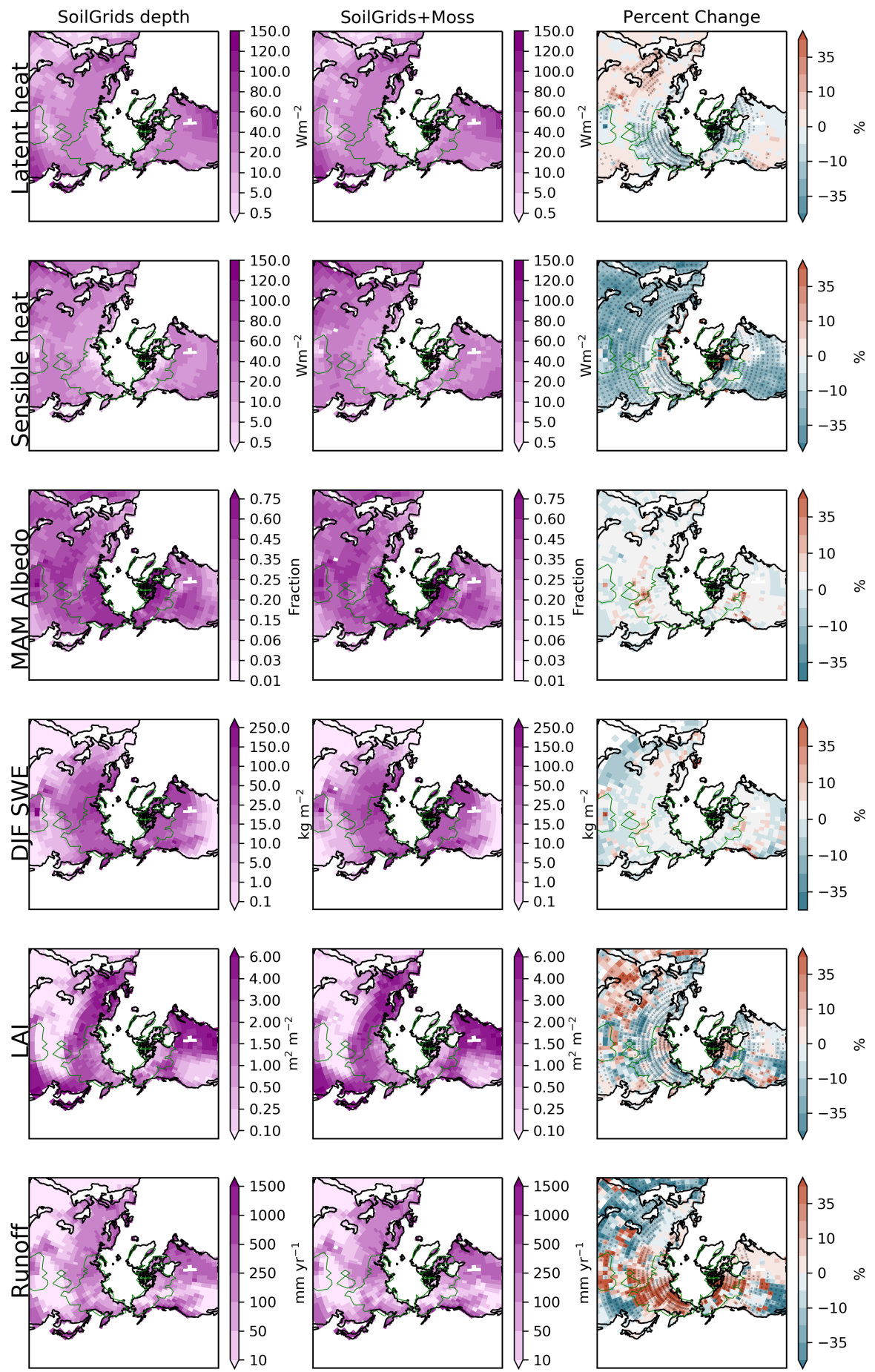

Figure S4. Same as Figure S3 but for experiments SoilGrids depth and SoilGrids+Moss 

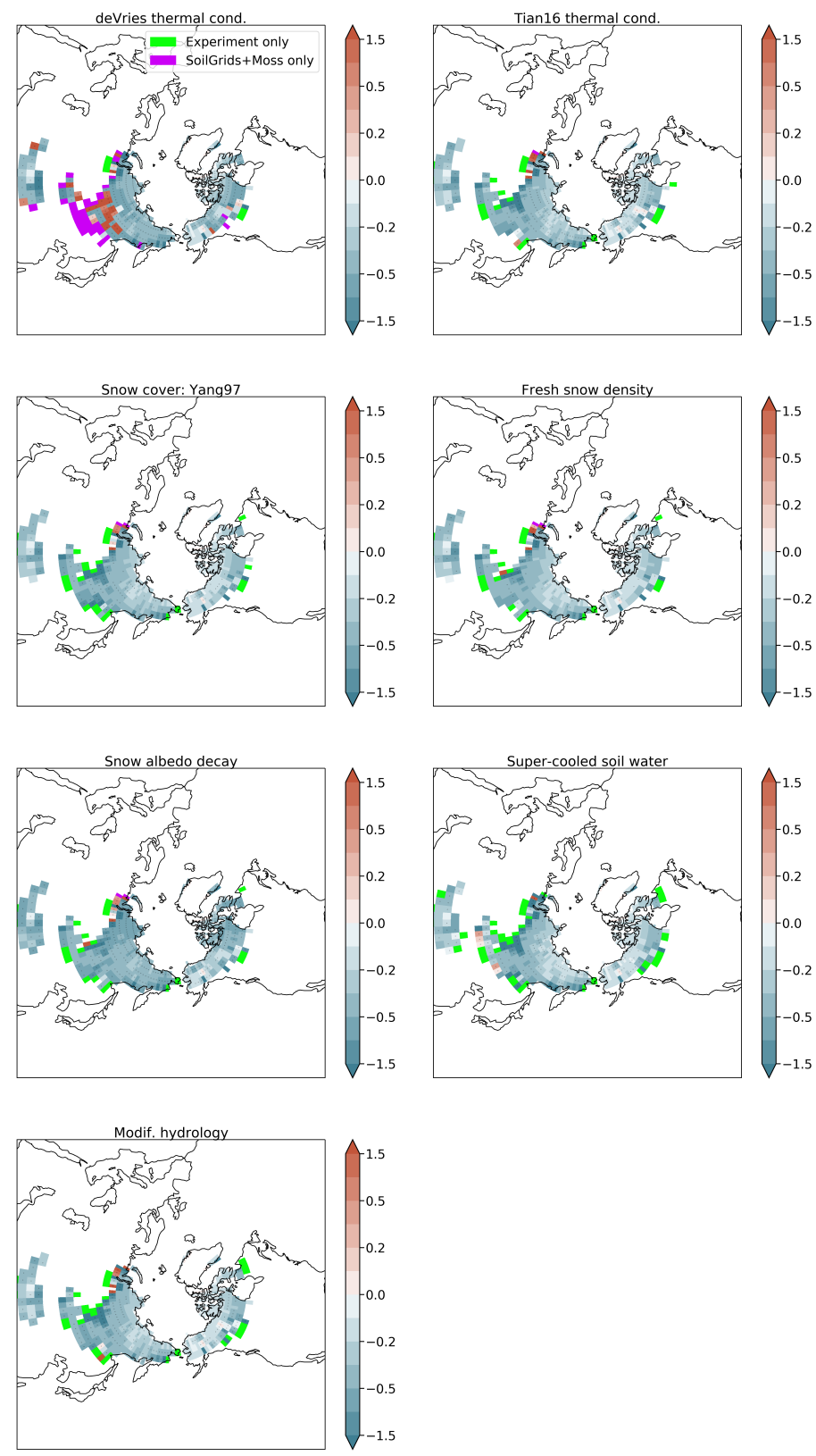

Figure S5. Differences (meters) between the SoilGrids+Moss simulated ALT and the ALT simulated by the alternative parameterization experiments (based on the model setup of SoilGrids+Moss, see Main Table 1). Negative values indicate that ALTs of the experiment are deeper than in SoilGrids+Moss while positive values indicate shallower ALTs. Since permafrost free soils have an undefined ALT, model grid cells that have permafrost in only the experiment are green while cells that have permafrost only in the SoilGrids+Moss simulation are purple. Dots indicate grid cells that are statistically significant (independent two-sample t-test p level $<0.05$ ). 


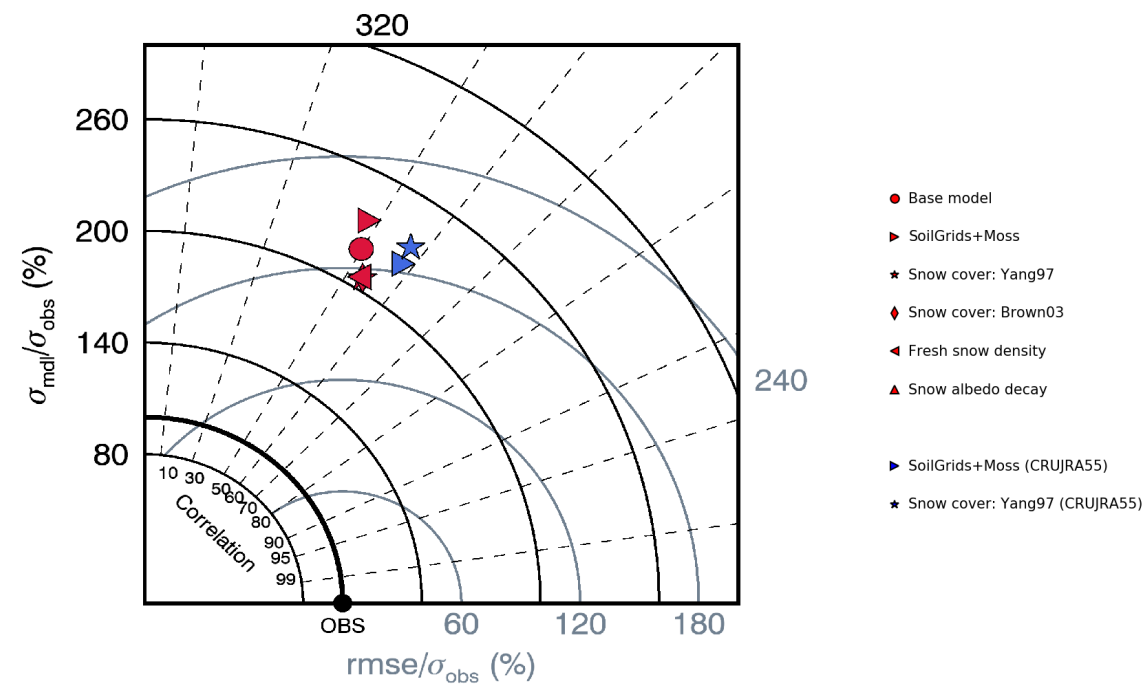

Figure S6. Taylor diagrams for winter (DJF) SWE compared to Blended-5 for the period spanning January 1981 to December 2010. Blended5 is a multi-dataset SWE product developed by Mudryk et al. (2015) that combines five observation-based SWE datasets. Exp. Snow albedo decay is outside the plot boundaries. This plot shows anomaly correlation coefficient as well as ratio of standard deviations and root mean square error normalized by the standard deviation from observations. Values shown correspond to the centroid over the values obtained for every grid cell northward of $45^{\circ} \mathrm{N}$, with climatological SWE $>4 \mathrm{~mm}$ to avoid regions of ephemeral snow. 


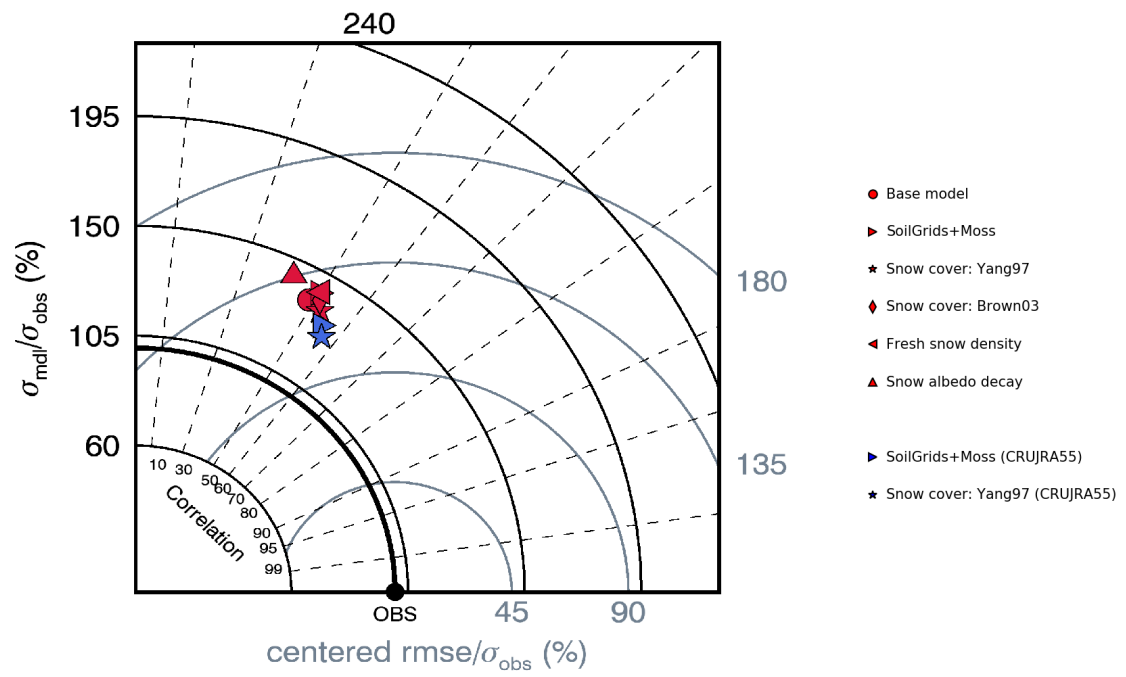

Figure S7. Taylor plot of total spring albedo (AMJ) compared to MODIS MCD43C3 white-sky albedo (MODIS Adaptive Processing System, NASA, 2016) for the period spanning February 2000 to December 2013. The Taylor plot shows the anomaly correlation coefficient (polar coordinates), ratio of standard deviations (y axis) and root mean square error (RMSE) normalized by the standard deviation from observations (x axis). Values shown correspond to the centroid over the values obtained for every grid cell northward of $45^{\circ} \mathrm{N}$. 


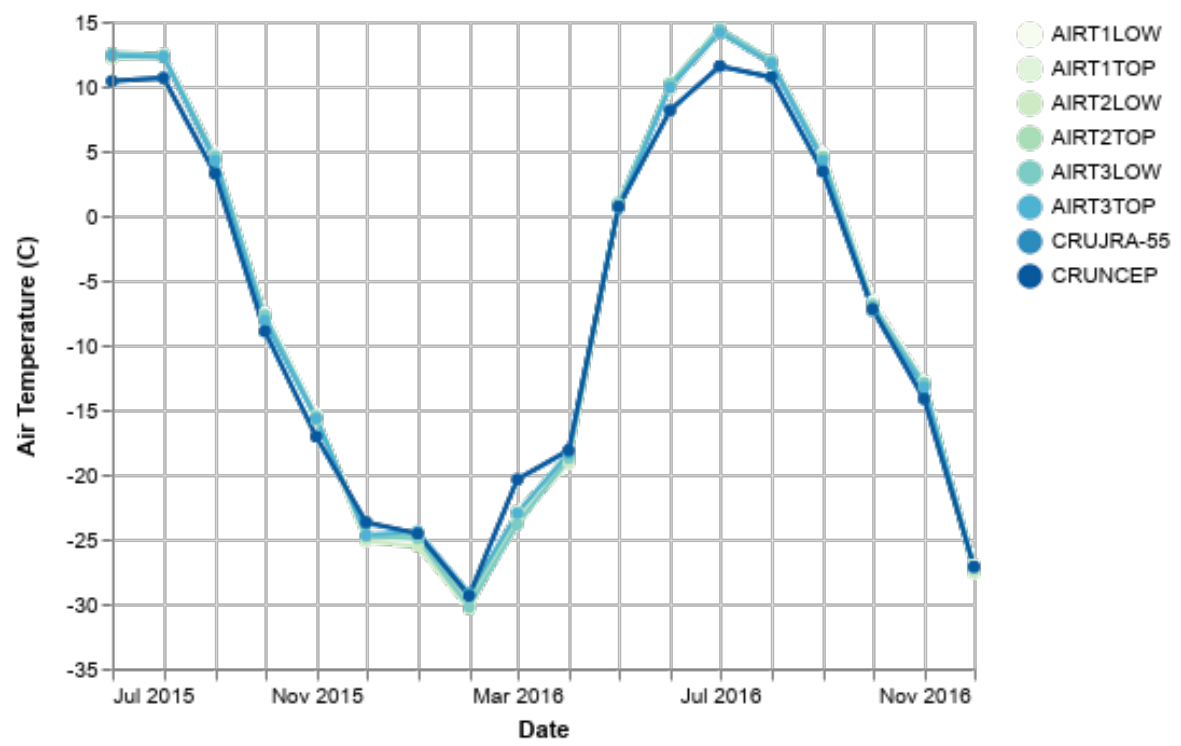

Figure S8. Mean monthly $2 \mathrm{~m}$ air temperature at Lac de Gras sites from meteorological stations as part of the Slave Province Surficial Materials and Permafrost Study (SPSMPS) (Gruber et al., 2018) and reanalysis meterological datasets CRUNCEP (Viovy, 2016) and CRUJRA55 (Harris et al., 2014; Kobayashi et al., 2015) 

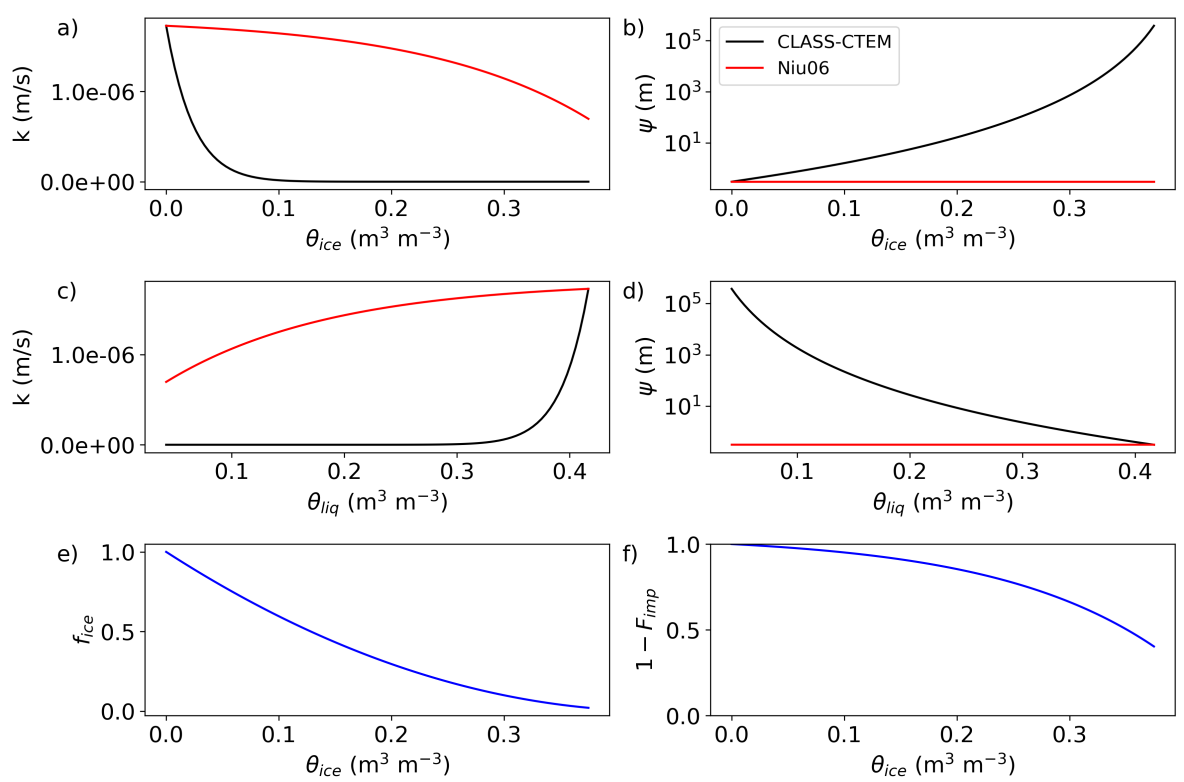

Figure S9. Soil hydraulic conductivity (a,c) and matric potential (b,d) for a soil with sand and clay content by weight of $40 \%$ and $20 \%$, respectively, with a maximum saturation level of $95 \%$. The Zhao and Gray (1997) $f_{i c e}$ and the Niu and Yang (2006) (1- $\left.F_{i m p}\right)$ parameters are shown in plots e and f, respectively. 

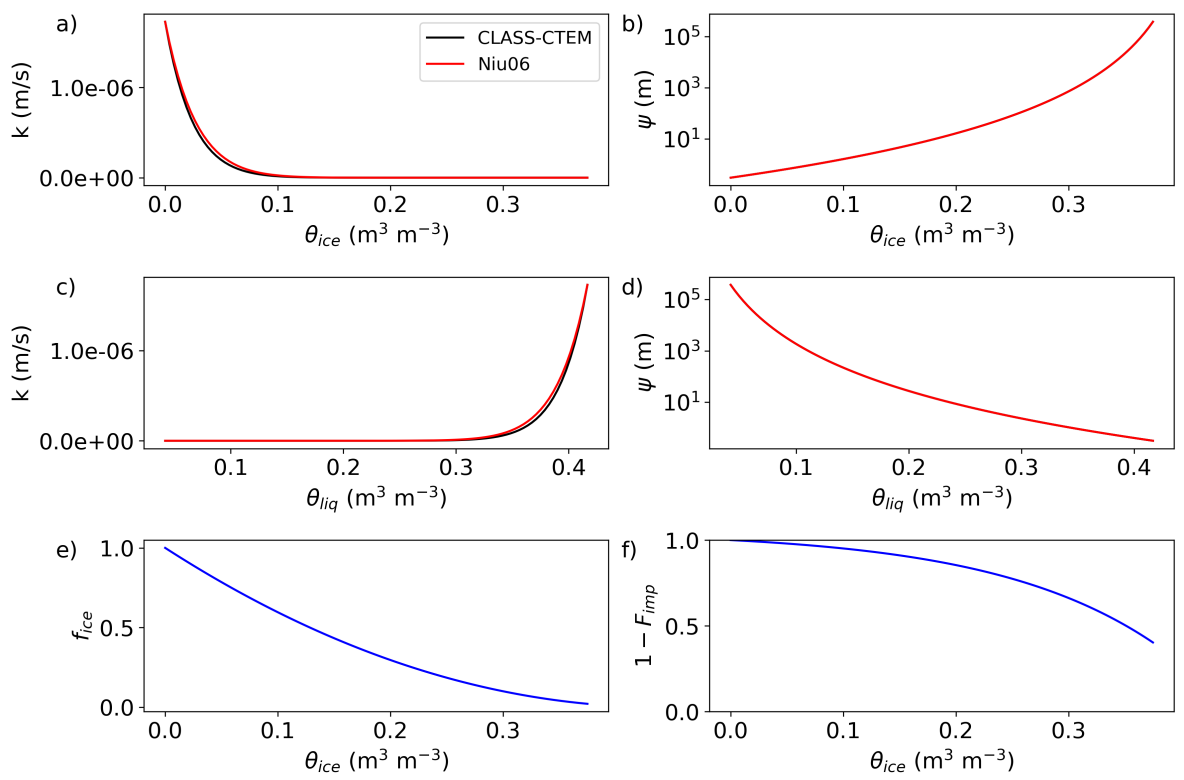

Figure S10. Same as Figure S9 but the $\theta_{i c e}$ term is removed from the numerator of equations B6 and B7. 

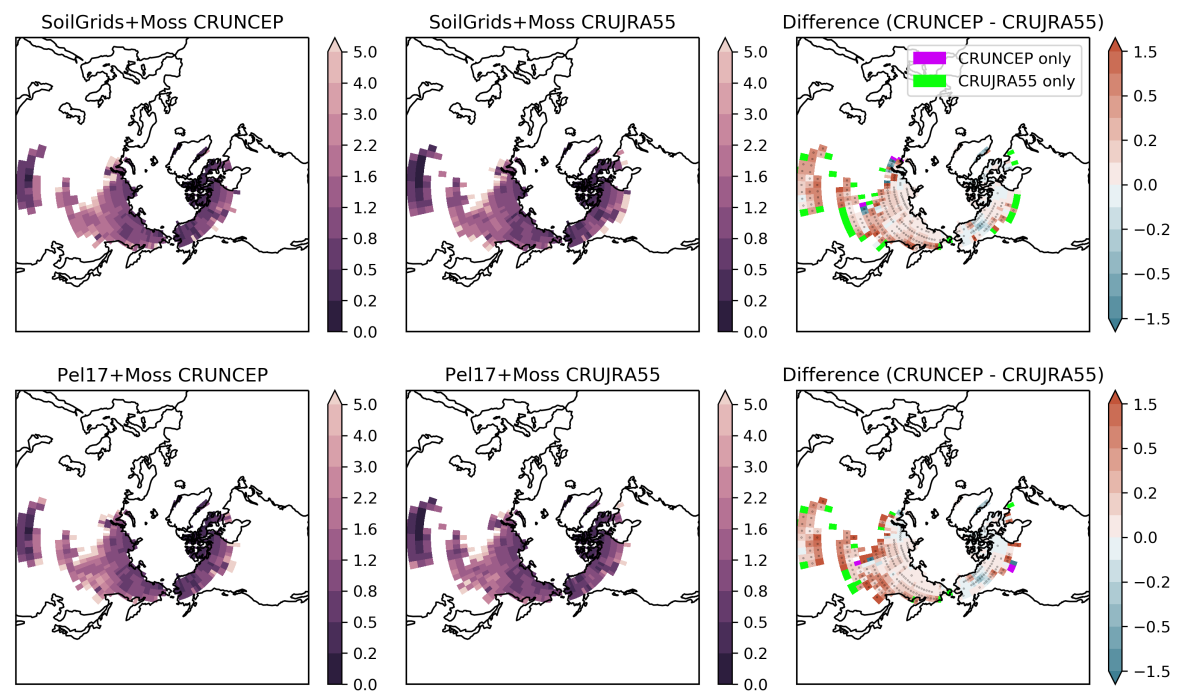

Difference (CRUNCEP - CRUJRA55)
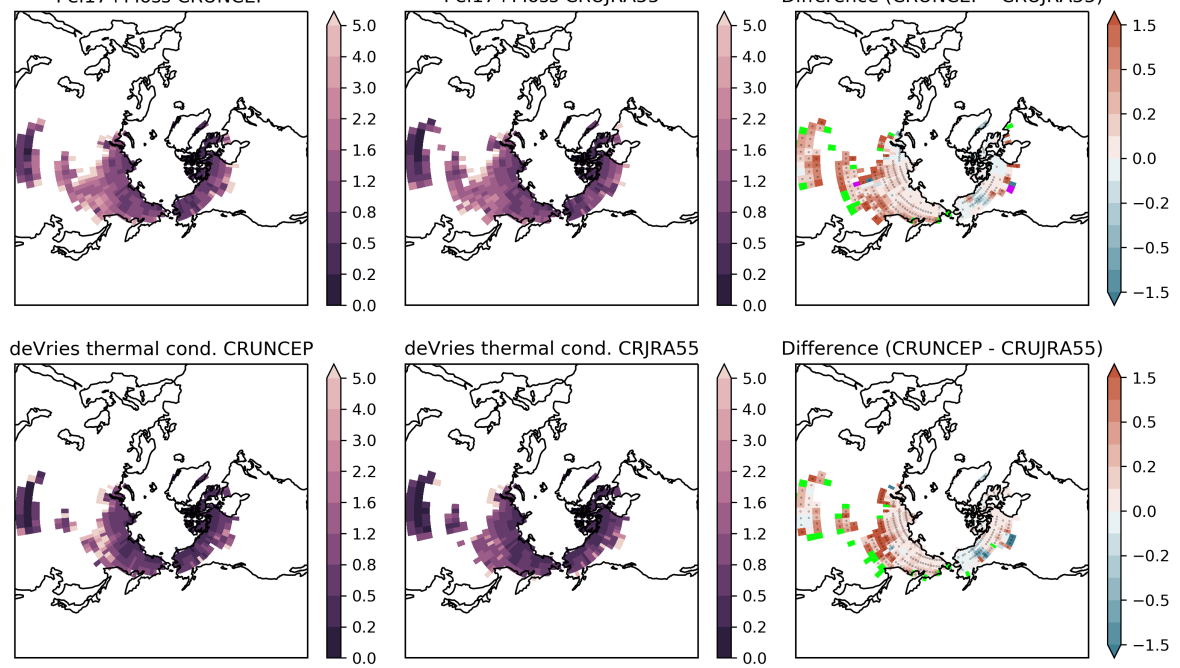

Difference (CRUNCEP - CRUJRA55)
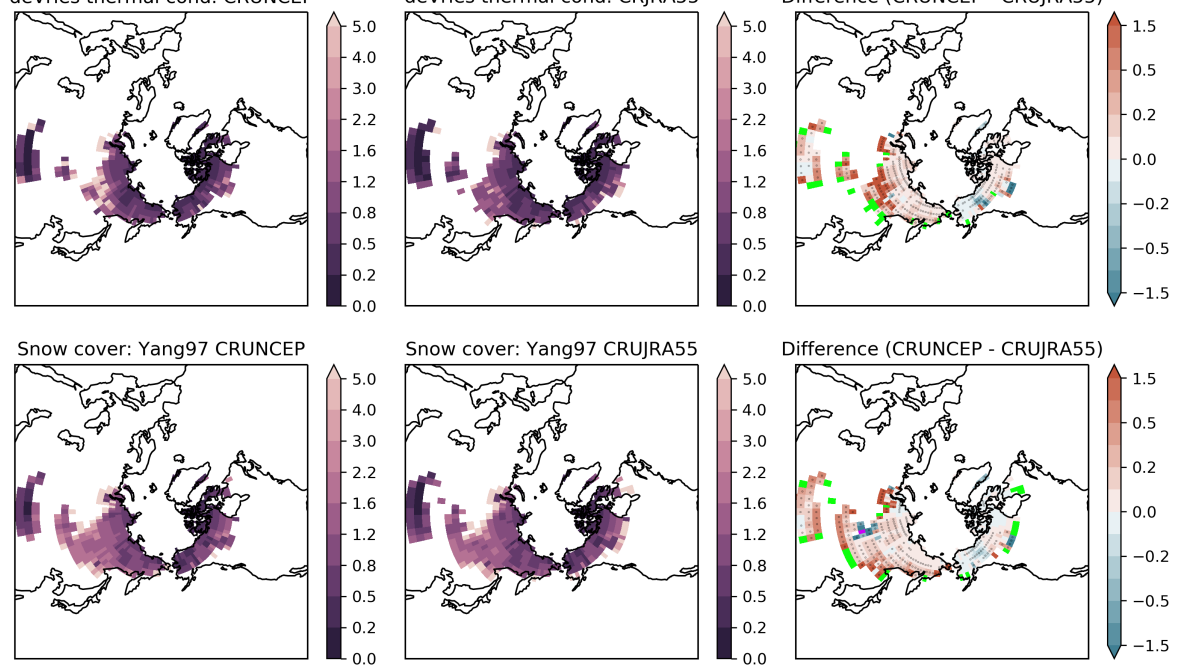

Difference (CRUNCEP - CRUJRA55)

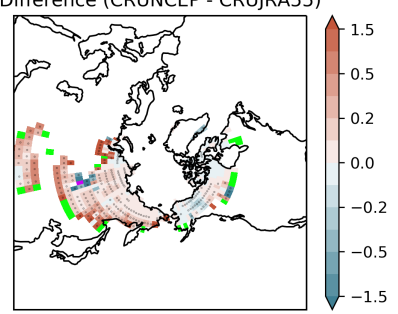

Figure S11. ALTs for experiments SoilGrids+Moss, Pel16+Moss, deVries thermal cond., and Snow cover: Yang97 using the CRUNCEP meterological forcing dataset (left column), CRUJRA55 meteorological forcing dataset (middle column), and their difference (right column). Dots indicate grid cells that are statistically significant (independent two-sample t-test $\mathrm{p}$ level $<0.05$ ). 


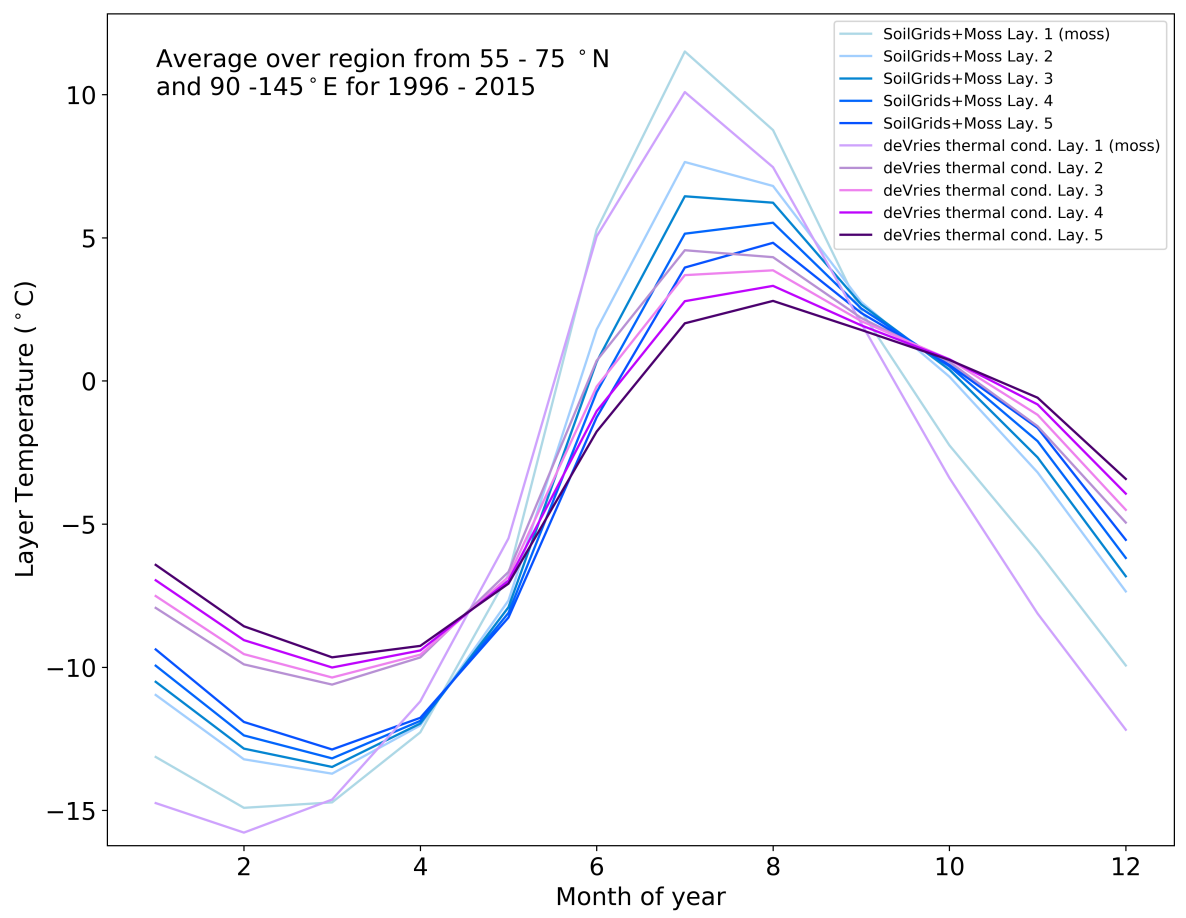

Figure S12. Mean monthly soil temperature over a permafrost region in eastern Siberia for the top 5 ground layers for the SoilGrids + Moss and deVries thermal cond. experiments. The first layer is moss in both simulations. 


\section{References}

Beer, C., Porada, P., Ekici, A., and Brakebusch, M.: Effects of short-term variability of meteorological variables on soil temperature in permafrost regions, The Cryosphere, 12, 741-757, 2018.

Brown, R. D., Brasnett, B., and Robinson, D.: Gridded North American monthly snow depth and snow water equivalent for GCM evaluation, Atmosphere-Ocean, 41, 1-14, https://doi.org/10.3137/ao.410101, 2003.

Côté, J. and Konrad, J.-M.: A generalized thermal conductivity model for soils and construction materials, Can. Geotech. J., 42, 443-458, https://doi.org/10.1139/t04-106, 2005.

de Vries, D.: Thermal properties of soils, Physics of Plant Environment, 1963.

Gruber, S., Brown, N., Stewart-Jones, E., Karunaratne, K., Riddick, J., Peart, C., Subedi, R., and Kokelj, S.: Air and ground temperature, air humidity and site characterization data from the Canadian Shield tundra near Lac de Gras, Northwest Territories, Canada, v. 1.0 (2015-2017), http://www.cen.ulaval.ca/nordicanad/dpage.aspx?doi=45561XD-2C7AB3DCF3D24AD8, https://doi.org/10.5885/45561XD-2C7AB3DCF3D24AD8, accessed: 2018-11-13, 2018

Harris, I., Jones, P. D., Osborn, T. J., and Lister, D. H.: Updated high-resolution grids of monthly climatic observations-the CRU TS3. 10 Dataset, Int. J. Climatol., 34, 623-642, 2014.

15 Kobayashi, S., Ota, Y., Harada, Y., Ebita, A., Moriya, M., Onoda, H., Onogi, K., Kamahori, H., Kobayashi, C., Endo, H., Miyaoka, K., and Takahashi, K.: The JRA-55 Reanalysis: General Specifications and Basic Characteristics, Journal of the Meteorological Society of Japan, 93, 5-48, https://doi.org/10.2151/jmsj.2015-001, 2015.

MacDonald, M. K.: The Hydrometeorological Response to Chinook Winds in the South Saskatchewan River Basin, Ph.D. thesis, University of Edinburgh, 2015.

20 MODIS Adaptive Processing System, NASA: MODIS/Terra+Aqua Albedo 16-Day L3 Global 0.05Deg CMG V005, title of the publication associated with this dataset: MODIS/Terra+Aqua Albedo 16-Day L3 Global 0.05Deg CMG V005, 2016.

Mudryk, L. R., Derksen, C., Kushner, P. J., and Brown, R.: Characterization of Northern Hemisphere snow water equivalent datasets, 19812010, Journal of Climate, 28, 8037-8051, 2015.

Niu, G.-Y. and Yang, Z.-L.: Effects of Frozen Soil on Snowmelt Runoff and Soil Water Storage at a Continental Scale, J. Hydrometeorol., 7 , 937-952, https://doi.org/10.1175/JHM538.1, 2006.

Pelletier, J. D., Broxton, P. D., Hazenberg, P., Zeng, X., Troch, P. A., Niu, G., Williams, Z. C., Brunke, M. A., and Gochis, D.: Global 1-km Gridded Thickness of Soil, Regolith, and Sedimentary Deposit Layers, https://doi.org/10.3334/ORNLDAAC/1304, 2016.

Shangguan, W., Hengl, T., Mendes de Jesus, J., Yuan, H., and Dai, Y.: Mapping the global depth to bedrock for land surface modeling, J. Adv. Model. Earth Syst., 9, 65-88, https://doi.org/10.1002/2016MS000686, 2017.

30 Verseghy, D.: CLASS - The Canadian land surface scheme (v. 3.6.2), Climate Research Division, Science and Technology Branch, Environment Canada, 2017.

Viovy, N.: CRU-NCEP Version 8, title of the publication associated with this dataset: CRU-NCEP version 8, 2016.

Yang, Z.-L., Dickinson, R. E., Robock, A., and Vinnikov, K. Y.: Validation of the snow submodel of the Biosphere-Atmosphere Transfer Scheme with Russian snow cover and meteorological observational data, J. Clim., 10, 353-373, 1997.

35 Zhao, L. and Gray, D. M.: A parametric expression for estimating infiltration into frozen soils, Hydrological Processes, 11, 1761-1775, https://doi.org/10.1002/(SICI)1099-1085(19971030)11:13<1761::AID-HYP604>3.0.CO;2-O, https://onlinelibrary.wiley.com/doi/abs/10. 1002/\%28SICI\%291099-1085\%2819971030\%2911\%3A13\%3C1761\%3A\%3AAID-HYP604\%3E3.0.CO\%3B2-O, 1997.

Zobler, L.: A world soil file for global climate modelling, title of the publication associated with this dataset: NASA Technical Memorandum $87802,1986$. 